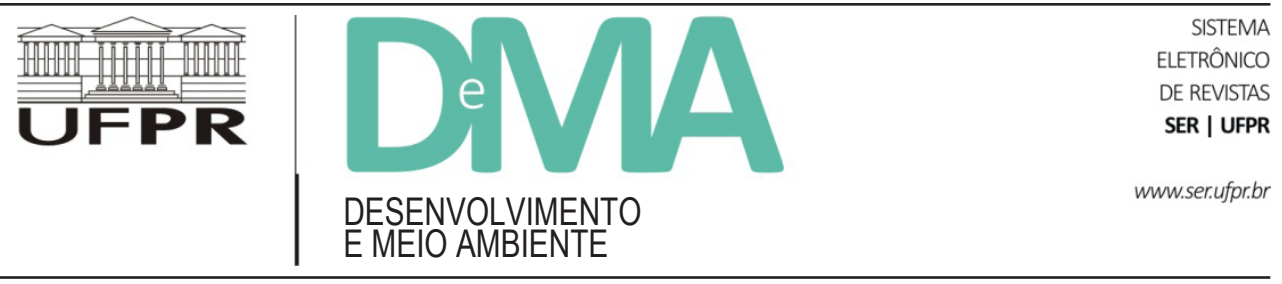

\title{
Sítios naturais sagrados: valores ancestrais e novos desafios para as políticas de proteção da natureza
}

\section{Sacred Natural Sites: Ancient Values and New Challenges for Nature Protection Policies}

\author{
Érika FERNANDES-PINTO ${ }^{1,2 *}$, Marta de Azevedo IRVING ${ }^{2}$ \\ ${ }^{1}$ Instituto Chico Mendes de Conservação da Biodiversidade, Brasília, DF, Brasil. \\ ${ }^{2}$ Programa EICOS de Pós-Gradução em Psicossociologia de Comunidades e Ecologia Social, Universidade Federal do Rio de Janeiro (UFRJ), \\ Rio de Janeiro, RJ, Brasil. \\ "E-mail de contato: erika.icmbio@gmail.com
}

Artigo recebido em 27 de julho de 2016, versão final aceita em 25 de fevereiro de 2017.

RESUMO: Em décadas recentes, um novo tema vem adquirindo visibilidade crescente nas discussões internacionais sobre estratégias de proteção da natureza - os sítios naturais sagrados. Entretanto, o conhecimento sobre esse tema, na maior parte dos países do mundo, é limitado, e as iniciativas de reconhecimento e salvaguarda dessas áreas em políticas públicas nacionais são ainda incipientes. A identificação de que muitos desses sítios estão sujeitos a diversas pressões e ameaças tem alertado pesquisadores e organizações globais para a importância de se promover estratégias para a sua proteção. Todavia, para que as diretivas formuladas internacionalmente possam se refletir em ações concretas de manejo dos sítios em seus contextos locais, é importante compreender como essa temática vem sendo interpretada no âmbito das políticas públicas e as tendências desse debate. Com o intuito de aprofundar essa reflexão, este artigo tem por objetivo contextualizar, criticamente, o panorama internacional e os caminhos em curso para o reconhecimento e a salvaguarda de sítios naturais sagrados, particularmente na relação com estratégias de proteção da natureza. A análise foi desenvolvida a partir da interpretação dos acordos firmados com esse objetivo, em nível mundial, embasada em pesquisa bibliográfica e documental. A complexidade que perpassa esse debate vem delineando uma série de desafios a serem transpostos para a gestão de áreas protegidas e deve inspirar novos caminhos para a leitura da indissociabilidade entre sociedade e natureza e para o resgate da sacralidade dessa relação.

Palavras-chave: sítios naturais sagrados; proteção da natureza; políticas públicas; valores espirituais; áreas protegidas.

ABSTRACT: In recent decades, a new topic has been gaining visibility in the international discussions on nature protection strategies - sacred natural sites. However, in most countries of the world, the knowledge on this subject is limited and the initiatives for inclusion of this theme in national public policy are still incipient. The recognition that many of these areas have been under pressure and threat has alerted researchers and international organizations 
to the importance of promoting strategies to protect sacred sites. However, it is important to understand how this subject has been interpreted in the context of global public policy and the trends of this debate in order to enable international guidelines to be reflected in concrete actions of sites management in their local contexts. To deepen this reflection, this paper critically contextualizes the international view and ways to recognize and safeguard sacred natural sites, notably in relation to nature protection strategies. The analysis was developed through the interpretation of worldwide agreements with this purpose, based on bibliographic and documentary research. The complexity of this debate is outlining a number of challenges to be overcome in order to manage protected areas. It should inspire new ways of viewing the inseparability between society and nature; and rescue the sacredness of this relationship.

Keywords: sacred natural sites; nature protection; spiritual values; protected areas.

\section{Introdução}

Ao longo da história da humanidade, diversas visões de mundo e concepções de natureza vêm sendo construídas e ressignificadas, consolidando a base cultural a partir da qual os grupos humanos estabelecem as suas relações sociais e resultando, também, em diferentes formas de percepção e interação com o ambiente. Na contemporaneidade, importantes paradoxos têm delineado o modelo de desenvolvimento adotado pela sociedade hegemônica, o qual é fundamentado em uma visão de cisão e dicotomia entre sociedade e natureza, o que vem contribuindo para um processo contínuo de degradação e agravamento dos problemas socioambientais em escala planetária (Guattari, 1990; Moscovici, 2007; Morin \& Kern, 2011; Loureiro, 2012; Irving, 2014).

Essa conjuntura tem suas raízes históricas na visão materialista e cientificista que vem influenciando o pensamento ocidental, principalmente a partir do século XVII. A problemática contemporânea está fundamentada na compartimentalização do conhecimento na interpretação da realidade, na ruptura entre ciência e espiritualidade e em uma visão de dessacralização da natureza. Como consequência, a crise atual, além de abranger questões ambientais, assume múltiplas facetas, com profundos reflexos também nas relações sociais e suas interfaces com as dimensões psicológicas e éticas (Guattari, 1990; Boff, 1999; Leff, 2001; Morin \& Kern, 2011).

Entretanto, distintas percepções de mundo vêm também se perpetuando na história da humanidade, especialmente entre povos indígenas e outros grupos de populações tradicionais cujos sistemas de crenças e modos de vida em geral estão vinculados a uma profunda sabedoria acerca da natureza, o que se reflete em uma outra forma de interagir com o ambiente, distinta daquela predominante na civilização ocidental hegemônica. Na cosmovisão desses grupos, todos os aspectos da vida estão interligados, e os elementos da natureza traduzem valores culturais e espirituais intrínsecos, representados sob seus domínios visíveis e invisíveis (Berkes, 1999; Posey, 1999). Os valores sagrados desses povos, em relação à natureza, estão frequentemente associados a locais específicos, imbuídos de significados e características singulares, denominados, na literatura especializada, como sitios naturais sagrados (SNS) ${ }^{1}$ (Verschuuren et al., 2010).

\footnotetext{
${ }^{1}$ Uma tradução direta do original em inglês - sacred natural sites.
} 
Os SNS incluem uma grande variedade de feições morfológicas e podem ser entendidos como "áreas de terra ou de água com um significado espiritual especial para povos e comunidades" (Wild \& McLeod, 2008, p. 5). A consagração de lugares sagrados representa uma prática muito antiga e propagada por todo o mundo. Eles são reconhecidos por povos indígenas, populações tradicionais, religiões institucionalizadas e outras filosofias espiritualistas, que lhes atribuem valores simbólicos, comumente envoltos em uma aura de mistério, magia e milagres (Fernandes-Pinto \& Irving, 2015).

Ao expressarem valores ancestrais e a visão de sacralidade da natureza de muitos grupos sociais, esses sítios, percebidos como parte fundamental de seus territórios, têm se revelado também como valiosos refúgios de biodiversidade (Wild \& McLeod, 2008; Dudley et al., 2010; Verschuuren et al., 2010). Todavia, a identificação de que muitas dessas áreas estão sujeitas a diversas pressões e ameaças tem alertado pesquisadores e organizações globais para a importância de se promover estratégias para a sua proteção.

Por essas razões, em décadas recentes, a temática dos SNS vem adquirindo uma visibilidade crescente em eventos internacionais promovidos por diversas instituições e com a publicação de algumas obras de referência, que têm reforçado a importância de se promover ações para o seu mapeamento e salvaguarda. Entretanto, o conhecimento sobre esse tema, em grande parte dos países do mundo, é limitado. Do mesmo modo, iniciativas de proteção dessas áreas em políticas públicas nacionais são ainda incipientes (Thorley \& Gunn, 2007; Wild \& McLeod, 2008; Verschuuren et al., 2010).

Para que o debate e as recomendações formuladas em nível mundial possam se refletir em ações concretas de manejo dos SNS nos seus contextos locais, é importante compreender como essa temática vem sendo interpretada no âmbito das políticas públicas globais e as tendências desse debate. Assim, este artigo tem por objetivo contextualizar, criticamente, o panorama internacional e os caminhos em curso para o reconhecimento e a salvaguarda de SNS, particularmente na relação com estratégias de proteção da natureza.

Para tanto, a análise foi desenvolvida a partir da interpretação dos acordos firmados com esse objetivo, em nível mundial, fundamentada em uma pesquisa qualitativa nas bases documentais da Organização das Nações Unidas para a Educação, a Ciência e a Cultura (UNESCO) e da União Internacional para a Conservação da Natureza (IUCN), complementada ainda por revisão bibliográfica sobre o tema em questão. Com o intuito de aprofundar a reflexão, buscou-se também identificar os principais desafios a serem enfrentados para a integração dos SNS nos sistemas governamentais de áreas protegidas, à luz das experiências internacionais.

\section{Os Sítios Naturais Sagrados e sua importância para a conservação da biodiversidade}

Em várias partes do mundo, determinados elementos da natureza - como montanhas, vulcões, formações rochosas, rios, lagos, cachoeiras, nascentes, bosques, cavernas e ilhas - podem ser considerados, por diversos grupos humanos, como lugares dotados de características especiais ou extraordinárias. Essas áreas essencialmente naturais, em muitos casos, são consagradas com símbolos e artefatos produzidos pelos seres humanos - como esculturas, pinturas, objetos e imagens religiosas - ou estão associadas a edificações como templos, santuários, mosteiros 
e igrejas ${ }^{2}$. Elas podem estar relacionadas, ainda, com caminhos históricos ou rotas de peregrinação religiosa (Thorley \& Gunn, 2007).

Alguns SNS são conhecidos mundialmente - como o Monte Sinai, no Egito; o Monte Shasta, na Califórnia/EUA; o Monte Everest, na fronteira da China com o Nepal; o Lago Titicaca, na divisa da Bolívia com o Peru, e o Rio Ganges, na Índia -, atraindo visitantes e peregrinos de várias partes do mundo. Diversos sítios são consagrados apenas no âmbito de uma determinada cultura e outros podem, ainda, estar envoltos pelo segredo, sendo poucos os indivíduos autorizados a acessá-los (Thorley \& Gunn, 2007).

As razões para a condição de sacralidade de cada sítio podem ser muito variadas. Em geral, eles são reconhecidos como lugares que têm uma energia ou força especial, perceptivelmente distinta da paisagem circundante. Eles também são interpretados como locais de morada de divindades e de espíritos ancestrais, podem ter relação com alinhamentos astronômicos e fenômenos sazonais, ou serem percebidos como fonte de recursos especiais como águas sagradas e plantas de poder ou medicinais. Alguns SNS estão, ainda, associados a eventos significativos na história de um determinado grupo social ou com suas lendas e mitos (Thorley \& Gunn, 2007; Wild \& McLeod, 2008).

Ao constituírem-se em lugares de grande significância cultural, os sítios sagrados desempenham, muitas vezes, um papel primordial para a vitalidade e a sobrevivência das identidades dos povos a eles relacionados. Além disso, um mesmo SNS pode ter importância para mais de uma tradição espiritual ou religiosa e ser reconhecido por uma gama de organizações socioculturais. Alguns deles remontam ao período pré-histórico e a povos de culturas já extintas. Contudo, também existem sítios que vêm sendo reconhecidos, revitalizados ou ressignificados por grupos sociais contemporâneos, em resposta a novas circunstâncias culturais ou mudanças do ambiente (Verschuuren et al., 2010).

As pesquisas realizadas nesse campo indicam que os SNS são encontrados em todos os continentes e, provavelmente, em todos os países do mundo. E, apesar de ainda não ser possível quantificar os sítios existentes - tendo em vista a diversidade de contextos nos quais eles ocorrem e as heterogeneidades de suas características -, estima-se que globalmente eles devem somar algumas centenas de milhares (Thorley \& Gunn, 2007).

Em geral, os SNS são interpretados como espaços de inspiração, revelação, cura, reverência e comunhão com a natureza e são visitados e utilizados em ocasiões especiais, para a realização de cerimônias ou rituais. Além disso, em função de seu valor espiritual, os sítios sagrados frequentemente são objeto de proteção voluntária dos grupos sociais a eles relacionados, muitas vezes há centenas de anos. E podem estar associados a regras de acesso, restrições à ocupação de determinadas áreas e limitações no uso dos seus recursos naturais. Nessa direção, uma série de pesquisas realizadas nos últimos anos vem demonstrando que o significado cultural atribuído a esses locais tem favorecido também a manutenção de áreas naturais bem conservadas. Por essas características, os SNS são reportados, por diversos autores, como as áreas

\footnotetext{
${ }^{2}$ Deste modo, Thorley \& Gunn (2007) identificaram a ocorrência de um espectro de situações que vão desde sítios sagrados mantidos totalmente sem intervenções humanas e lugares em que elementos antrópicos foram agregados sem descaracterizar as suas características naturais; até situações em que construções de maior porte praticamente encobrem as feições originais, o que leva, em muitos casos, a uma dificuldade de categorizar o que é estritamente natural do que tem um caráter exclusivamente antrópico.
} 
de conservação mais antigas do planeta e, ao longo da história, como uma importante estratégia para a proteção da natureza (Dudley et al., 2005; Wild \& McLeod, 2008; Dudley et al., 2010).

Em apoio a esse argumento, o estudo realizado por Dudley e colaboradores (2010), em particular, merece destaque. Ao compilar e analisar uma série de trabalhos científicos que buscaram investigar o valor da biodiversidade em SNS, os autores identificaram que esses sítios podem conter uma elevada riqueza biológica - por vezes superior a reservas florestais ou outras áreas protegidas situadas no seu entorno - e abrigar animais e plantas raros ou ameaçados de extinção. Alguns desses santuários podem estar localizados em regiões já bastante degradadas pelas intervenções humanas, representando, assim, valiosos refúgios remanescentes da biodiversidade local. Em muitas situações, no entanto, essas áreas encontram-se fortemente ameaçadas pela pressão antrópica crescente sobre os recursos naturais. Sendo assim, a percepção dos efeitos desse processo sobre a integridade de diversos sítios levou Dudley e colaboradores (2010) a enfatizarem, também, a necessidade de implementar instrumentos para a sua salvaguarda.

Diante desse contexto, a integração dos SNS às estratégias globais de proteção da natureza tem sido considerada como uma alternativa fundamental para resguardar os valores biológicos e culturais desses lugares singulares. Diversos autores, em revisões críticas sobre o tema, vêm chamando a atenção para o fato de que muitos dos SNS descritos na literatura, em vários países do mundo, encontram-se, de fato, em áreas protegidas legalmente instituídas pelo Poder Público (Dudley et al., 2005; Thorley \& Gunn, 2007; Wild \& McLeod, 2008). Esta representa uma problemática complexa em termos de gestão, à medida que valores culturais e espirituais estão também associados à importância ecológica das áreas protegidas, o que vem gerando novos desafios para os processos de formulação de políticas públicas com esse objetivo.

Para que se possa aprofundar a reflexão sobre os caminhos que têm sido percorridos para a integração dos SNS e seus valores associados à gestão de áreas protegidas, entretanto, é fundamental resgatar, ainda que brevemente, a perspectiva histórica de como as estratégias oficiais de proteção da natureza foram se constituindo em relação aos territórios dos povos nativos e os principais desafios dessa interação.

\section{Os caminhos para a integração dos sítios naturais sagrados às políticas públicas de proteção da natureza}

\section{1. Áreas protegidas e territórios de povos tradicionais: uma relação delicada}

A perspectiva de se resguardar parcelas representativas da diversidade natural, a partir da instituição das denominadas áreas protegidas (AP), tem se consolidado como a estratégia mais utilizada, em escala global, para a proteção da natureza. Esses espaços - definidos com áreas com limites reconhecidos com a finalidade de conservação da natureza, de seus serviços ecossistêmicos e dos valores culturais associados (Dudley, 2008) - estão, atualmente, no cerne do debate sobre a relação entre sociedade e natureza.

Essa conjuntura decorre do fato da expansão dessas áreas formalmente protegidas no mundo vir implicando em algumas contradições, inerentes a um processo ainda em construção, especialmente ao se considerar suas interfaces com os territórios de povos indígenas e outras populações tradicionais. Para entender esse contexto, é importante resgatar a 
perspectiva histórica de como essa relação foi sendo estabelecida ao longo do tempo.

As origens do movimento para a criação de AP remetem ao final do século XIX, nos Estados Unidos, com a instituição do Parque Nacional de Yellowstone, em 1872, a partir de onde esse modelo se propagou, progressivamente, para outros países. No contexto mundial, as AP tiveram uma rápida expansão - principalmente a partir da década de 1970 - chegando a uma estimativa da existência, na atualidade, de mais de 200 mil áreas formalmente reconhecidas pelos governos nacionais, envolvendo aproximadamente $15 \%$ da superfície terrestre global e 3,4\% dos oceanos (Juffe-Bignoli et al., 2014).

A criação de AP é considerada a mais importante estratégia de conservação da natureza e relevantes acordos mundiais vêm sendo firmados com vistas a ampliar a representatividade dessa rede em nível global. Entretanto, esse processo também vem sendo acompanhado por críticas crescentes a esse modelo de proteção ambiental, em virtude dos custos sociais da sua implementação e questionamentos quanto à sua real eficácia (Bensusan, 2014; Dudley et al., 2014).

Parte desse conflito pode ser explicado pelo fato de que, desde a sua gênese, a noção de áreas protegidas se constituiu a partir de uma visão dicotômica sobre a relação sociedade e natureza que, como abordado anteriormente, tem influenciado o pensamento ocidental desde o século XVII. Deste modo, em grande parte dos países, as terras oficialmente designadas para proteção foram estabelecidas essencialmente como se fossem áreas de natureza virgem, baseadas no que Diegues (2008) denominou de o mito moderno da natureza intocada. Um processo muitas vezes impositivo, implantado desconsiderando a presença de povos nativos, bem como os usos preexistentes dos territórios e dos recursos naturais a eles associados.
A partir desse viés ideológico - que tem sido predominante no movimento conservacionista desde seus primórdios -, a presença de populações humanas nas AP, principalmente até a década de 1980, era considerada como um problema e uma ameaça para a natureza, independentemente das características culturais dos grupos sociais envolvidos. Em razão disso, mecanismos para a realocação de populações humanas dos limites dessas áreas foram frequentemente implementados pelo Poder Público para, em tese, equacionar essa questão. $\mathrm{Ou}$ então, severas restrições foram imputadas às suas práticas produtivas e formas de uso do território, o que muitas vezes inviabilizava a manutenção dos modos de vida tradicionais (West \& Brechin, 1991; Stevens, 1998; Beltrán, 2000; Bensusan, 2014).

Dessa forma, em diversos contextos, a instituição de AP vem sendo permeada por tensões entre diferentes visões de mundo, resultando em uma série de conflitos socioambientais, especialmente com relação a povos indígenas e outros grupos tradicionais. Nessa discussão, é relevante mencionar que a presença de povos nativos em áreas protegidas não representa um fato isolado. Essa situação pode ser identificada em cerca de $70 \%$ das AP do mundo e estima-se que, na América Latina, essa proporção deve alcançar mais de $80 \%$ das áreas instituídas. Por esse motivo, apesar da relevância das AP para a conservação da biodiversidade, vários autores vêm discutindo que essa estratégia também se constitui em uma prática socialmente excludente (Beltrán, 2000; Borrini-Feyerabend et al., 2004; Barreto-Filho, 2004; Dowie, 2011).

Desse quadro potencialmente conflituoso decorre uma série de implicações quanto ao modo pelo qual os sítios naturais sagrados vêm sendo incorporados e considerados na gestão das áreas protegidas. A fim de contribuir para esse debate, Dudley e colaboradores (2005) analisaram uma 
centena de casos de SNS localizados em AP legalmente instituídas, em vários países. A partir da análise realizada, puderam demonstrar que a criação e implementação dessas áreas têm ocorrido, comumente, sem uma avaliação prévia dos valores e dos usos, por vezes ancestrais, que esses territórios têm para as populações a eles vinculadas.

Em alguns contextos, no entanto, há também o reconhecimento de que a criação de uma AP pode efetivamente contribuir para a maior proteção dos SNS inseridos nos seus limites, especialmente quando eles estão sujeitos a pressões e ameaças oriundas de fontes externas, como a implantação de projetos de infraestrutura e atividades industriais. Entretanto, o que se observou, na maioria dos casos estudados por esses autores, foi que essa situação tende a gerar inúmeros conflitos envolvendo os grupos sociais e os administradores das AP, principalmente quando regras e restrições para o acesso e uso desses locais são impostas à população local sem consideração dos seus valores culturais (Wild \& McLeod, 2008).

Essa conjuntura decorre, principalmente, da ausência de reconhecimento dos SNS e dos significados a eles associados nos processos de gestão das AP, mas também do não entendimento das populações locais quanto aos objetivos das áreas protegidas (Dudley et al., 2005; Thorley \& Gunn, 2007). As consequências dessa conjuntura resultam em situações nas quais tanto os usos religiosos podem ter impactos negativos na conservação da biodiversidade como as atividades promovidas com a gestão das AP podem ser danosas para os sítios sagrados ou ofensivas frente aos valores culturais dos grupos sociais a eles relacionados (Higgins-Zogib, 2007).

Assim, apesar das evidências de que muitos SNS vêm representando áreas essenciais para a proteção da natureza ao longo da história, a sua importância nas estratégias mundiais de conserva- ção da biodiversidade tem sido pouco enfatizada e reconhecida pelos órgãos governamentais com competência para a execução dessas políticas públicas (Verschuuren, 2007; Verschuuren \& Wild, 2012).

Nas últimas décadas, no entanto, novas perspectivas no arcabouço legal internacional têm sido construídas, contemplando a noção de interdependência entre cultura e natureza, notadamente com a valorização dos conhecimentos e práticas tradicionais e a garantia de direitos territoriais dos povos indígenas e outros grupos sociais. Nesse contexto, os SNS vêm se configurando como um tema emergente em pesquisas científicas e em debates internacionais sobre proteção da natureza, e se destacando como um dos principais desafios na perspectiva estratégica de implantação e gestão das áreas protegidas, na atualidade.

\subsection{Novas abordagens em politicas públicas integrando natureza e cultura}

O período que compreende meados da década de 1990 até a época atual vem sendo marcado pela aprovação de uma série de acordos internacionais que tem gerado repercussões significativas - direta ou indiretamente - para as iniciativas de reconhecimento dos SNS, a partir de novas abordagens em políticas públicas integrando natureza e cultura.

Ainda no início da década de 1990, a Convenção sobre Diversidade Biológica (CDB) - aprovada no âmbito da Conferência das Nações Unidas sobre Meio Ambiente e Desenvolvimento, realizada no Rio de Janeiro/Brasil, em 1992 - representou um dos primeiros marcos para o reconhecimento da importância dos saberes tradicionais para a proteção da natureza. Ao expressar como objetivo "a conservação da biodiversidade, o uso sustentável de seus componentes e a divisão equitativa e justa 
dos benefícios gerados com a utilização de recursos genéticos" (Ministério do Meio Ambiente, 2000, p. 9), essa convenção reconheceu também que à biodiversidade estão associados valores culturais intrínsecos.

Nessa perspectiva, o dispositivo mais emblemático da CDB é o seu artigo 8j, que, entre outros aspectos, solicita aos países membros da Organização das Nações Unidas que "respeitem, preservem e mantenham o conhecimento, as inovações e as práticas das comunidades indígenas e locais que incorporam estilos de vida tradicionais relevantes para a conservação e o uso sustentado da diversidade biológica" (Ministério do Meio Ambiente, 2000, p. 12). Essa Convenção, já adotada por mais de 190 países, vem se consolidando como a principal referência mundial sobre questões de proteção da natureza e tem se desdobrado em uma série de iniciativas com reflexos diretos na discussão sobre a salvaguarda dos SNS.

Um exemplo que ilustra essa assertiva foi a publicação, em 2004, das Diretrizes Voluntárias Akwé:Kon. Esse documento, construído no escopo da CDB, inovou o debate em curso ao abordar a necessidade de serem realizadas avaliações também das repercussões sociais e culturais de projetos de desenvolvimento que possam afetar lugares sagrados ou terras ocupadas e utilizadas tradicionalmente por povos indígenas (Secretariat of the Convention on Biological Diversity, 2004). Ao enfatizar a relevância dos SNS frente a outras políticas públicas setoriais, esse documento vem se configurando como um importante referencial para a proteção desses locais.
Entre os acordos mundiais negociados com essa perspectiva, cabe ressaltar, nessa análise, algumas políticas de proteção do patrimônio cultural, como a Declaração Universal sobre a Diversidade Cultural (UNESCO, 2001), a Convenção para Salvaguarda do Patrimônio Cultural Imaterial (UNESCO, 2003) e a Convenção sobre a Proteção e a Promoção da Diversidade das Expressões Culturais (UNESCO, 2005). Essas normativas vêm se constituindo em dispositivos fundamentais para o reconhecimento das dimensões simbólicas e dos valores intangíveis associados ao patrimônio natural, fortalecendo o debate sobre a importância dos SNS nos processos de conservação da biodiversidade

Entretanto, é importante destacar que, apesar da Convenção do Patrimônio Mundial (1972), ser considerada o primeiro instrumento global a abordar natureza e cultura conjuntamente, as práticas de registro e tombamento dos bens assim reconhecidos ainda são operadas sob a égide da divisão entre essas duas dimensões ${ }^{3}$. De acordo com Larsen \& Wijesuriya (2015), esse representa um desafio a ser ainda enfrentado, mas inevitável, de revisão dessa política, com o intuito de reconhecer e afirmar a diversidade biocultural. Esse novo conceito considerado mais holístico, dinâmico e integrador - vem emergindo em meio a esse debate a partir da compreensão de natureza e cultura como dimensões interdependentes a compor a rede da vida (Maffi \& Woodley, 2010).

É essencial destacar também a aprovação, em 2007, da Declaração Universal dos Direitos dos Povos Indigenas (UNDRIP). Ao reconhecer e afirmar os direitos fundamentais universais no contexto das

\footnotetext{
${ }^{3}$ A avaliação dos bens propostos para inscrição na Lista do Patrimônio Mundial na categoria cultural é feita pelo International Council of Monuments and Sites- ICOMOS e na categoria natural, pela IUCN. No caso dos bens inscritos como patrimônio misto ou na categoria paisagem cultural, essas duas organizações são mantidas como responsáveis por avaliar os quesitos culturais e naturais de cada caso, separadamente.
} 
culturas indígenas, essa diretiva, cuja construção se prolongou por 25 anos de debates e controvérsias, representou uma conquista primordial para o avanço na consolidação dos direitos desses grupos sociais. As proposições da UNDRIP vêm contribuindo, desde então, para o estabelecimento de diretrizes políticas e legislações nacionais que reforçam o papel dos povos indígenas na manutenção da diversidade biocultural. O artigo 12 desse documento, em particular, ao afirmar que "os povos indígenas têm o direito [...] de manter e proteger seus lugares religiosos e culturais, e de ter acesso a esses de forma privada", representa uma real inspiração para o desenvolvimento de políticas públicas dirigidas ao reconhecimento e proteção dos SNS (Nações Unidas, 2008, p. 9).

Considerando-se os pressupostos e as proposições desse arcabouço legal, é possível observar que um crescente reconhecimento dos direitos dos povos indígenas e outras populações tradicionais vem se consolidando nas últimas décadas, assim como a afirmação do relevante papel desses grupos sociais em políticas públicas dirigidas à proteção da natureza. Além disso, esses acordos enfatizam também o entendimento de que valores espirituais, além de elementos-chave da diversidade cultural, têm importância fundamental para a conservação da riqueza biológica, o que tende a influenciar novas perspectivas na interpretação da problemática dos SNS e das ideologias associadas ao debate sobre a relação sociedade e natureza, na contemporaneidade.
Mas, qual a relevância atribuída aos SNS no debate global relativo à formulação de políticas públicas de proteção da natureza? E como esses lugares, seus valores e significados têm sido considerados nos processos de gestão das áreas protegidas? Com o intuito de aprofundar essa reflexão buscar-se-á, a seguir, identificar os marcos de inserção da temática dos SNS nos principais fóruns mundiais sobre proteção da natureza. A partir desse panorama, serão interpretados os desafios essenciais a serem transpostos para o reconhecimento e a salvaguarda dessas áreas, bem como as tendências que vêm sendo delineadas em consonância com as estratégias de conservação da biodiversidade.

\subsection{Sítios naturais sagrados em debate: do reconhecimento do conflito à busca de soluções compartilhadas}

No histórico do desenvolvimento de políticas públicas setoriais, duas grandes organizações internacionais têm tido um papel central e uma importância fundamental na definição das bases, regras e tendências mundiais para o reconhecimento e a salvaguarda dos SNS no mundo. Por um lado, a UNESCO, que atua nas questões relativas ao patrimônio natural e cultural mundial ${ }^{4} \mathrm{e}$, por outro, a IUCN, a partir da ênfase atribuída às estratégias mundiais para a proteção da natureza ${ }^{5}$.

Com esse direcionamento, uma série de iniciativas e eventos organizados por essas instituições,

\footnotetext{
${ }^{4}$ A UNESCO, fundada em 1945, é uma organização internacional que tem por missão contribuir para a paz mundial, a erradicação da pobreza, o desenvolvimento sustentável e o diálogo intercultural por intermédio da educação, da ciência, da cultura, da comunicação e da informação (Fonte: www.unesco.org).

${ }^{5}$ A IUCN, fundada em 1948, é considerada a maior e mais antiga organização ambientalista mundial. Consiste em uma rede global que tem por missão encontrar soluções para a conservação ambiental e o desenvolvimento sustentável. Congrega mais de 1.300 organizações de 161 países, incluindo mais de 200 agências governamentais e 1.000 não governamentais, em uma parceria mundial única. Tem cerca de 16 mil pesquisadores e especialistas voluntários registrados, agrupados em seis comissões temáticas (Fonte: www.iucn.org).
} 
notadamente a partir do final da década de 1990 e ao longo dos anos 2000, vem contribuindo para a construção de caminhos possíveis para a internalização da importância dos SNS em políticas públicas e, particularmente, na gestão de áreas protegidas. Como será apresentado na sequência, ao longo desse período, alguns marcos podem ser destacados como inspiradores para o debate atualmente em curso. $\mathrm{Na}$ Tabela 1, a seguir, são listados os principais eventos internacionais relacionados à temática dos SNS, promovidos pela UNESCO e IUCN em colaboração com outras instituições.

Nessa retrospectiva, o seminário intitulado Sitios Naturais Sagrados: diversidade biológica e cultural, organizado pela UNESCO e outras instituições parceiras e realizado em 1998 na França, pode ser considerado como o primeiro evento internacional que teve os SNS como temática principal. Esse encontro congregou pesquisadores de diversas áreas de conhecimento, que apresentaram mais de 80 estudos de caso de diversas partes do mundo, reafirmando, como o título do evento sugere, os SNS como elos essenciais no processo de integração entre sociedade e natureza (UNESCO, 1998).

Essa premissa foi retomada em 2003, no Workshop Internacional A Importância dos Sítios Naturais Sagrados para a Conservação da Biodiversidade, também organizado pela UNESCO, na República Popular da China. Os diversos estudos de caso apresentados nesse evento, provenientes de países da África, da Ásia e da América Central, evidenciaram, com clareza, a contribuição que muitos

TABELA 1 - Principais eventos internacionais associados ao debate sobre a temática dos sítios naturais sagrados (1998-2016).

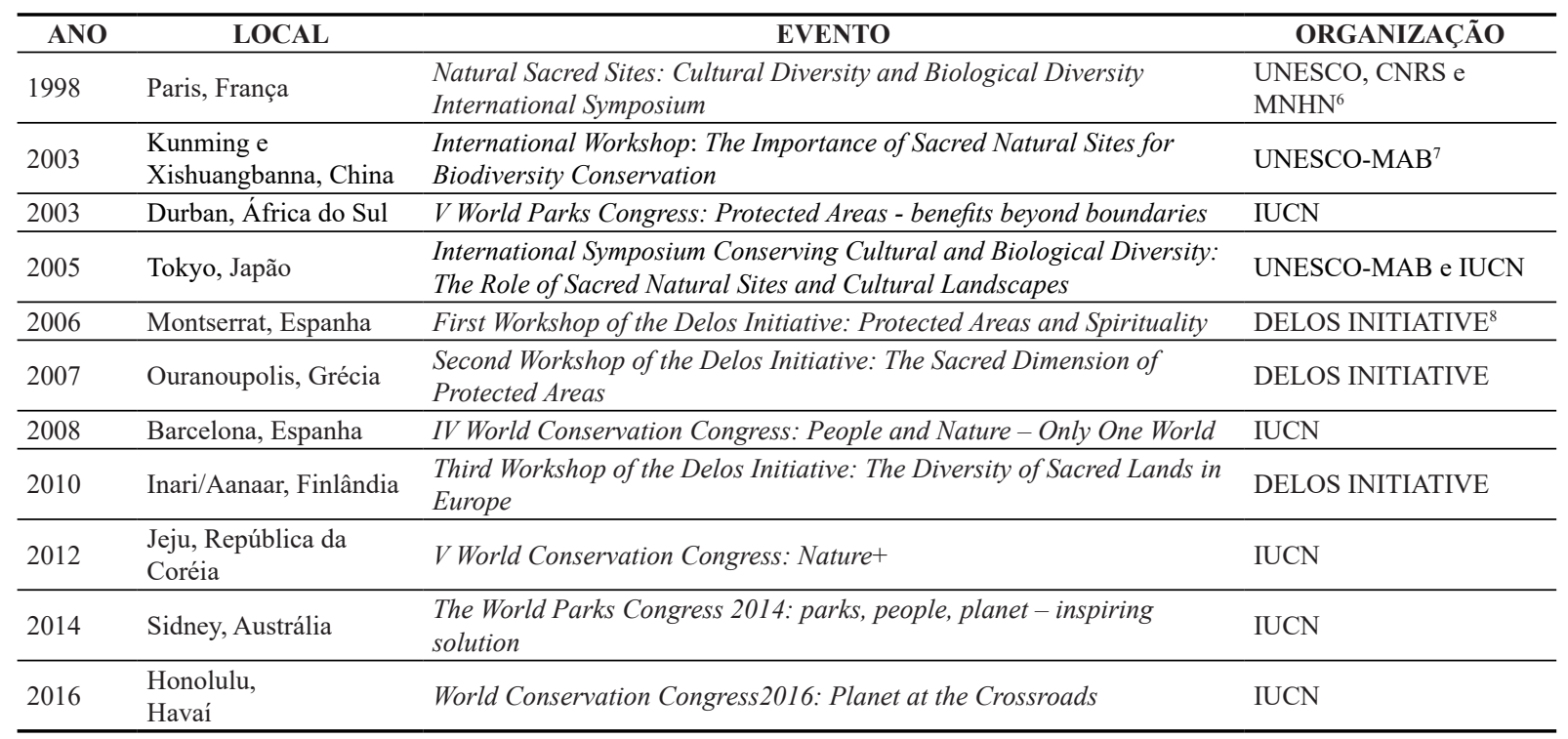

FONTE: organização das autoras.

${ }^{6}$ Centre National de la Recherche Scientifique (CNRS) e o Muséum National d'Histoire Naturelle (MNHN) da França.

${ }^{7}$ Programa Homem e Biosfera (MAB).

${ }^{8}$ Uma iniciativa apoiada pela Comissão Mundial de Áreas Protegidas da IUCN, centrada no estudo e salvaguarda de sítios naturais sagrados em países desenvolvidos (Fonte: www.med-ina.org/delos). 
SNS podem ter para os processos de proteção da natureza, o que suscitou também a discussão sobre a relevância desses espaços no âmbito do debate sobre as áreas protegidas (Lee \& Schaff, 2003).

Esses eventos pioneiros contribuíram para a sistematização de um escopo inicial de informações sobre o tema e para a reflexão sobre a importância dos SNS em nível mundial. Nessa discussão, alertou-se também para a urgência da realização de mais pesquisas e iniciativas que possam promover um maior conhecimento sobre o tema e as dinâmicas socioculturais a ele relacionadas. Esses encontros também viabilizaram o envolvimento de um conjunto de organizações internacionais nesse debate - como a World Wide Fund for Nature (WWF) e a The Nature Conservancy (TNC) - que se comprometeram a desenvolver, a partir de então, estratégias para integrar a perspectiva dos valores culturais e espirituais em seus programas de conservação da biodiversidade (Verschuuren et al., 2007). Dessa forma, esses primeiros eventos sobre os SNS foram essenciais para que tal temática se destacasse no plano global e fosse inserida, posteriormente, em fóruns mais amplos sobre políticas públicas de proteção da natureza, a exemplo dos congressos mundiais de parques e de conservação da natureza, organizados periodicamente pela IUCN ${ }^{9}$.

Especialmente relevante nesse processo foi o V Congresso Mundial de Parques, realizado em Durban/África do Sul, em 2003. Tendo como tema Áreas Protegidas: benefícios além das fronteiras, ele contou com a presença de cerca de 120 representantes de povos indígenas e outras populações tradicionais, originários de diversas partes do mundo - uma novidade com relação aos congressos anteriores promovidos pela instituição. De acordo com Brosius (2004), essas lideranças contribuíram para reafirmar a crítica ao modelo de criação de AP, especialmente no que tange ao envolvimento das populações locais. Na oportunidade, as lideranças presentes denunciaram também uma série de injustiças sofridas pelos grupos ali representados, como consequência da implantação dessa estratégia globalmente difundida nos processos de conservação da biodiversidade e de gestão territorial.

Como parte dos esforços para se alterar esse cenário, resultou do evento a aprovação de várias recomendações reconhecendo a relevância do papel de povos indígenas e outros grupos sociais para a proteção da natureza. Reforçou-se, por um lado, a legitimidade das suas formas tradicionais de manejo e gestão dos territórios e, por outro, a afirmação da importância dos valores culturais e espirituais associados às áreas protegidas.

Nesse sentido, particularmente marcante foi a concepção da noção de áreas de conservação comunitárias, definidas como

[...] ecossistemas naturais e modificados que possuem valores significativos em relação à biodiversidade, serviços ecológicos e valores culturais, conservadas voluntariamente por comunidades indígenas e locais por meio do direito consuetudinário e outros meios eficazes (IUCN, 2005, p. 202).

O reconhecimento dessas áreas no documento final do evento (refletido na Recomendação 5.26 - Incorporação das áreas conservadas por comunidades) evidenciou a necessidade de serem revistos diversos fundamentos orientadores dos sistemas oficiais de AP e de se considerar outros

\footnotetext{
${ }^{9}$ Os congressos mundiais de parques ocorrem a cada 10 anos e definem a agenda mundial para áreas protegidas. A primeira edição foi realizada em 1962, em Seattle/EUA, e a sexta e última, no final de 2014, em Sidney/Austrália. Já os congressos mundiais de conservação da natureza são organizados a cada dois anos e acontecem desde 1948. Sua última edição foi em setembro de 2016, no Havaí/EUA (Fonte: www.iucn.org).
} 
valores e pontos de vista nas estratégias de proteção da natureza, a partir da perspectiva dos grupos sociais locais.

$\mathrm{Na}$ ocasião, foram emblemáticas também a discussão sobre a relevância do uso das áreas protegidas com propósitos espirituais, bem como a reafirmação da importância dos SNS nesses contextos, tanto como parte fundamental dos territórios e da cultura dos povos tradicionais como para a conservação da biodiversidade. Além disso, foi enfatizada a necessidade de se proteger as áreas naturais de especial valor e significado cultural com a aprovação da Recomendação 5.13 - Reconhecimento dos Valores Culturais e Espirituais das Áreas Protegidas (IUCN, 2005, p. 168).

O passivo de conflitos envolvendo povos indígenas na implementação de estratégias de proteção da natureza também foi reconhecido, reafirmando-se os direitos desses grupos em participar dos processos de tomada de decisão e de utilizar e gerir os SNS de acordo com as suas normas e práticas culturais. Foi reforçado, ainda, que os valores espirituais são essenciais em todas as categorias de manejo de AP e, portanto, segundo o debate realizado, devem ser levados em consideração nas diversas etapas para a sua criação, implantação e gerenciamento (Recomendação 5.19 - Sistema de categorias da IUCN para a gestão das áreas protegidas) (IUCN, 2005, p. 182).

Como consequência desses encaminhamentos, o V Congresso Mundial de Parques de Durban/2003 é reconhecido, na atualidade, como o ponto de virada do movimento mundial de proteção da natureza em direção a um novo paradigma de conservação. Esse também se constitui no primeiro evento de impacto global a partir do qual os SNS passaram formalmente a fazer parte da agenda de discussão sobre áreas protegidas no mundo (Wild \& McLeod, 2008).

\subsection{Ampliando o conhecimento sobre os SNS nas áreas protegidas e estabelecendo diretrizes para a sua gestão}

Na sequência dos debates e encaminhamentos do congresso de Durban/2003, foi formado, no âmbito da Comissão Mundial de Áreas Protegidas da IUCN ${ }^{10}$, o Cultural and Spiritual Values of Protected Areas Specialist Group (CSVPA), que congrega especialistas de vários países. A partir do trabalho desse grupo, diversas iniciativas para a investigação e a promoção da importância de tais valores vêm sendo realizadas, contribuindo para ampliar o conhecimento sobre os SNS nas AP e para avanços no debate sobre estratégias para o seu reconhecimento e proteção ${ }^{11}$.

Entre as atividades da CSVPA direcionadas à divulgação de informações sobre sítios sagrados, destaca-se a publicações dos livros The Full Values of Parks: from economics to the intangible (Harmon \& Putney, 2003); Sacred Natural Sites: conserving nature \& culture (Verschuuren et al., 2010) e Sacred Species and Sites: advances in biocultural conservation (Pungetti et al., 2012), importantes referências para o debate em curso. Destaca-se também a construção do Silene Documentation Center, uma base de dados digital com mais de 250 publicações relacionadas com SNS e a importância dos valores culturais e espirituais na conservação da natureza

\footnotetext{
${ }^{10}$ Do original em inglês, a World Comission on Protected Areas (WCPA). Essa é uma das seis comissões voluntárias da IUCN, formada por administradores de áreas protegidas e especialistas. Tem por objetivo promover o estabelecimento e a administração efetiva de uma rede de trabalho mundial sobre o tema (Fonte: www.iucn.org).

${ }^{11}$ Disponível em: <www.silene.es/>. Acesso em: mar. 2017.
} 
Com o apoio da CSVPA, foram organizados, principalmente na segunda metade da década de 2000, alguns eventos que reuniram especialistas sobre o tema para discutir estudos de caso de SNS de várias partes do mundo. Entre eles, podem ser mencionados: 1) o Seminário Internacional Conservando Diversidade Biológica e Cultural: o papel dos sítios naturais sagrados e das paisagens culturais, em Tóquio/Japão, em 2005; 2) o I Workshop da Iniciativa Delos Áreas Protegidas e Espiritualidade, em Montserrat/Espanha, em 2006 e 3) o II Workshop da Iniciativa Delos Dimensões Sagradas das Áreas Protegidas, em Ouranoupolis/ Grécia, em 2007.

Os resultados dos trabalhos e dos debates realizados nesses eventos - publicados respectivamente em Schaaf \& Lee (2006), Mallarach \& Papayannis (2007) e Papayannis \& Mallarach (2009) - representam um substancial conjunto de referências bibliográficas que permite traçar um panorama geral sobre a situação dos SNS no mundo e ilustrar a abrangência e a diversidade de contextos nos quais eles podem ser encontrados. Esses estudos vêm também contribuindo para ampliar o entendimento sobre a importância cultural e ambiental dos sítios sagrados e para embasar a formulação de estratégias para o seu reconhecimento e proteção.

Nesse contexto, é relevante também assinalar que esses eventos chamaram a atenção para o fato de que, em todos os países analisados nos estudos mencionados anteriormente, a integridade de muitos SNS encontra-se ameaçada. Esse quadro decorre tanto das pressões oriundas de fontes externas de desenvolvimento e implantação de projetos de infraestrutura como também de uma série de dinâmicas internas relativas aos próprios grupos sociais a eles relacionados, suscetíveis a mudanças de valores e de costumes que podem gerar processos de desestruturação cultural. Reconhecendo-se os múltiplos riscos a que muitas dessas áreas estão sujeitas, vêm sendo também intensas, desde então, as discussões para a ampliação das iniciativas de integração dos SNS nos sistemas formais de áreas protegidas. Nessa direção, os resultados dos eventos internacionais sobre SNS reforçaram, ainda, a necessidade de se desenvolver mecanismos e instrumentos legais que proporcionem uma efetiva proteção desses sítios, não só para aqueles situados no interior das áreas protegidas.

Essas ações vêm contribuindo ativamente para delinear as políticas de atuação da IUCN sobre o tema, fornecendo informações que resultaram na aprovação de diversas resoluções e recomendações nos congressos mundiais de parques e de conservação da natureza subsequentes, conforme será abordado na continuidade do artigo.

Outro desdobramento importante desses encontros foi a elaboração de um texto de referência para o manejo de SNS em áreas protegidas (AP), voltado para os administradores dos órgãos oficiais incumbidos de sua gestão, intitulado Sacred Natural Sites: Guidelines for Protected Area Managers, compilado por Wild \& McLeod (2008) e publicado pela IUCN em parceria com a UNESCO. Lançado no IV Congresso Mundial de Conservação da $\mathrm{Na}$ tureza, realizado em Barcelona/Espanha, em 2008, nesse documento está expresso que os SNS podem estar associados a todas as tipologias de AP, desde aquelas de uso sustentável até as categorias de manejo mais restritivas, nas quais não se permite, teoricamente, o uso direto de recursos naturais.

As mais de 40 diretrizes desse documento envolvem recomendações para a ampliação do reconhecimento dos SNS e dos valores a eles associados nos processos de planejamento e gestão de AP legalmente designadas. Também é reafirmada a importância da promoção da participação e da inclusão dos atores sociais envolvidos, a partir da 
construção de um processo de colaboração respeitosa entre os administradores de AP e os guardiões tradicionais desses sítios (Wild \& McLeod, 2008).

Essa publicação pioneira oferece um panorama geral sobre o estado da arte da gestão dos SNS em áreas protegidas e também apresenta uma gama de exemplos de boas práticas que estão sendo desenvolvidas em diferentes partes do mundo. Alguns casos emblemáticos retratados nesse documento são o do Parque Nacional do Tongarino, na Nova Zelândia e o reconhecimento de seu valor cultural e espiritual para o Povo Maori como patrimônio da humanidade; a gestão do uso público no Monumento Nacional Devils Tower nos Estados Unidos, em conformidade com os usos religiosos indígenas; e as adaptações na gestão da AP que inclui o Pico Sri Pada-Adams no Sri Lanka, para acomodar interesses multirreligiosos, entre outras (Wild \& McLeod, 2008).

Entretanto, os especialistas reconheceram que, apesar da existência de algumas iniciativas localizadas de manejo promissoras, a gestão de SNS em áreas protegidas, na maioria dos países, encontra-se ainda em estágio incipiente. Isso implica na necessidade de se promover estratégias para que se possa traduzir as diretrizes e recomendações internacionais em políticas públicas em âmbitos nacionais e locais (Wild \& McLeod, 2008).

Ainda com relação ao Congresso de Barcelona/2008, é importante destacar a aprovação, na ocasião, de uma resolução específica sobre o reconhecimento da relevância da conservação de SNS em áreas protegidas (a Resolução 4.038). Além de explicitar os problemas gerados pela instituição de AP sem o reconhecimento dos sítios sagrados em seu interior, essa diretiva ressalta a premência de se promover estratégias de diálogo entre os grupos sociais a eles associados e os interlocutores da gestão pública, para a mediação dos conflitos identificados. O texto em questão reforça uma série de pontos abordados no congresso anterior, em Durban/2003, reforçando a sua consonância com a aprovação de novas políticas de reconhecimento dos direitos dos povos indígenas e tradicionais - como a UNDRIP e o compromisso com a sua implementação (IUCN, 2008, p.42-43).

Nessa direção, a resolução aprovada em Barcelona, mencionada anteriormente, também expressa a necessidade de se adotar estratégias para garantir o consentimento prévio e informado desses grupos para a realização de qualquer ação que possa afetar, direta e/ou indiretamente, os seus sítios sagrados e o seu território de forma geral. Para tal, o documento traz a proposta de que os SNS sejam identificados como áreas de conservação comunitárias e que essas, por sua vez, sejam formalmente incorporadas às políticas públicas de proteção da natureza. Nessa resolução é ainda enfatizada a pertinência de se estimular a realização de pesquisas e projetos para a aplicação prática das diretrizes internacionais para gestão de SNS em AP ${ }^{12}$ (Wild \& McLeod, 2008).

Também foi aprovada, nessa ocasião, a $R e$ solução 4.099 - Reconhecimento de diversidade de conceitos e valores da natureza. Essa diretiva considera a conservação da natureza como uma ação humana enraizada em diversas culturas - envolvendo suas cosmovisões, práticas e tradições. E insta os membros da IUCN a reconhecer, promover, apoiar e incorporar diversas maneiras de entender a relação entre sociedade e natureza e o valor do mundo

\footnotetext{
${ }^{12}$ No esforço de divulgação desse documento, seu texto já foi traduzido para sete línguas. Entretanto, ainda não há uma versão oficial em português. A CSVPA tem buscado estratégias para estimular que as diretrizes sejam aplicadas e testadas em diferentes contextos e também solicitado contribuições para a sua revisão com estudos de caso e sugestões.
} 
natural, a fim de ampliar os esforços interculturais para a conservação (IUCN, 2008, p. 120-212).

Nesse evento de 2008, foram de grande significância para o debate em questão a apresentação e ratificação do documento intitulado Um anúncio dos guardiões dos sítios e territórios naturais sagrados, elaborado por representantes de povos indígenas e outras populações tradicionais que participaram do congresso. Por meio dessa declaração, as lideranças presentes no congresso ressaltaram as ameaças a que muitos SNS estão sujeitos, enfatizando que esses territórios não podem ser analisados de forma dissociada das tradições culturais que os reconhecem e protegem. O texto também explicita a preocupação desses grupos com a transmissão dos saberes tradicionais associados às suas práticas espirituais e aos lugares sagrados para as novas gerações. Saliente-se ainda a menção à necessidade de apoio de instituições públicas e/ou não governamentais para o registro dessas informações e para a promoção de ações que valorizem esse conhecimento ${ }^{13}$.

Posteriormente ao evento de Barcelona, os SNS também estiveram em destaque no $V$ Congresso Mundial de Conservação da Natureza, realizado em Jeju, na República da Coréia, em 2012 $2^{14}$. Nesse evento foi aprovada uma recomendação em apoio ao desenvolvimento de protocolos comunitários bioculturais como uma estratégia para se garantir o protagonismo e a autonomia dos guardiões de SNS (na Recomendação 147 - Sítios Naturais Sagrados: apoio para protocolos dos guardiões e leis costumeiras face aos desafios e ameaças globais). Expressando a preocupação com as ameaças e pres- sões a que os SNS estão sujeitos - especialmente com relação aos impactos de projetos de desenvolvimento de infraestrutura e de exploração industrial de recursos naturais (como a mineração e a atividade madeireira) -, esses protocolos, construídos coletivamente, têm por finalidade estabelecer as diretrizes para a implantação de atividades que podem afetar esses territórios. Essa diretiva também inovou ao instar o setor empresarial a respeitar os direitos dos povos indígenas e a adotar os princípios e diretrizes para a proteção dos SNS. Além disso, foi destacada, na ocasião, a urgência em se desenvolver instrumentos legais para proteger a integridade biológica e cultural dessas áreas (IUCN, 2012, p. 204).

Alguns exemplos desse contexto vem sendo documentados também em produções cinematográficas como o Mine: Story of a Sacred Mountain (2009), sobre uma montanha sagrada na Índia ameaçada pela proposta de exploração de uma mina de bauxita; o Challenges of Sacred Groves e o Guardianship of the Sacred Groves (2012), sobre o movimento comunitário nas Ilhas de Zanzibar, na Tanzânia/África , contra um projeto de construção de uma rodovia que interceptaria um bosque de figueiras, uma árvore sagrada para os Hindus e o Huicholes: the Last Peyote Guardians (2014), que retrata uma mobilização nacional no México contra a concessão de licenças para mineração no território sagrado do deserto de Wirikuta ${ }^{15}$. Esses exemplos ilustram que a identificação de uma série de ameaças à integridade dos recursos naturais - a que tanto as áreas protegidas como os SNS estão sujeitos - tem

\footnotetext{
${ }^{13}$ Disponível em: <http://www.sacredland.org/media/Custodians-Statement-WCC-Barcelona.pdf>. Acesso em: fev. 2017.

${ }^{14}$ Entre os congressos mundiais da IUCN de Barcelona/2008 e de Jeju/2012, foi realizado ainda o III Workshop da Iniciativa Delos, em Inari na Finlândia, em 2010, que teve como tema A diversidade de terras sagradas na Europa (Mallarach et al., 2012).

${ }^{15}$ Disponíveis em: <https://vimeo.com/58632407> ; <https://vimeo.com/58897622>; <https://vimeo.com/12397686> e <https://huicholesfilm. com/>, respectivamente. Acesso em: jun. 2016.
} 
reforçado a busca por sinergias na articulação entre as estratégias de gestão desses territórios.

No congresso de Jeju/2012 foi aprovada também a Resolução 009, que considera que instituições religiosas e grupos baseados na fé podem ser valiosos aliados na proteção da natureza. Reconhecendo que diversas dessas organizações são proprietárias de santuários naturais e guardam SNS, bem como a grande influência que elas podem ter no comportamento e nos sistemas de valores da sociedade, essa diretiva encoraja o estabelecimento de alianças e parcerias com elas, reforçando a valorização da vida a partir de princípios éticos de sustentabilidade e justiça social (IUCN, 2012, p. 16).

\subsection{Os sítios naturais sagrados como inspiração para uma transformação global}

Entre os eventos mundiais que se configuram como marcos referenciais para o debate sobre os SNS em AP, cabe destacar, ainda, o VI Congresso Mundial de Parques, realizado em novembro de 2014, em Sidney/Austrália. Com o tema Parques, Pessoas, Planeta: inspirando soluções, a sua concepção teve como propósito a busca por formas inovadoras de inspirar as pessoas a buscarem uma conexão mais profunda com a natureza, envolvendo seus corações e mentes para gerar bem-estar físico, psicológico e espiritual. Essa edição do evento - realizada 11 anos depois do emblemático congresso anterior de Durban, em 2003 - avançou nas propostas de inserção social na gestão das áreas protegidas e demonstrou que os casos mais bem-sucedidos de conservação no mundo são aqueles que promovem parcerias com os diversos setores da sociedade.

$\mathrm{Na}$ busca da construção de uma noção de conservação da natureza fundamentada no envolvimento social e no sentido de pertencimento, os SNS foram tema de diversas iniciativas durante esse congresso. Entre elas, destaca-se o workshop intitulado Significância Cultural e Espiritual da Natureza no Manejo e Governança de Áreas Protegidas, que agregou gestores de AP, representantes de povos indígenas e outras populações tradicionais, líderes religiosos e de organizações da sociedade civil $^{16}$. Dessa atividade resultaram a formação de uma rede de pessoas interessadas no tema; a proposta de construção de um sítio eletrônico para dar suporte à iniciativa; o desenvolvimento de módulos de formação para apoiar processos de capacitação presenciais ou virtuais ${ }^{17}$; além de contribuições para a revisão e o aprimoramento das diretrizes para o manejo de SNS em AP da IUCN (Wild \& McLeod, 2008), com previsão de uma publicação revisada e atualizada desse documento em 2017.

O documento final desse congresso de 2014, intitulado A Promessa de Sidney, foi proposto como um ponto de referência para uma verdadeira transformação no processo de gestão das AP, reafirmando-se o papel dessas áreas em oferecer soluções inspiradoras e enfoques inovadores para grandes desafios mundiais como a redução da pobreza e da desigualdade social, a contenção de desastres ambientais e a perda da diversidade biológica, além

\footnotetext{
${ }^{16}$ Network and Best Practice Guidelines on the Cultural and Spiritual Significance of Nature in Protected Area Management and Governance. Disponível em: <https://csvpa4iucn.files.wordpress.com/2014/08/side-event-network-and-guidelines-on-cultural-and-spiritual-significance-of-nature.pdf>. Acesso em: fev. 2016.

${ }^{17}$ Nessa direção, a CSVPA lançou o Culture \& Espiritual Nature Programme, um programa voltado para a formação de gestores habilitados a atuar no reconhecimento e na promoção da significância cultural e espiritual da natureza no manejo e governança das áreas protegidas (Fonte: csvpa.org).
} 
de contribuírem como fonte de estímulo à paz, à saúde e ao bem-estar da sociedade e do planeta ${ }^{18}$. Entre os diversos compromissos formalizados nesse documento, 49 recomendações foram consideradas diretamente relevantes para o trabalho da CSVPA e para a temática dos SNS (Mallarach, 2014).

É importante salientar que nesse congresso foi reafirmado e reforçado um apelo mundial para a adoção do que está sendo denominada de uma nova ética na conservação, fundamentada em noções de justiça, equidade, reciprocidade e respeito para com os diversos grupos sociais, além da integração entre diversidade biológica e sociocultural. A Promessa de Sidney também convoca os estados nacionais e organizações ambientalistas a desenvolverem mecanismos concretos de reparação e restituição de terras aos povos indígenas e outros grupos tradicionais impactados por áreas protegidas, a exemplo do que ocorreu em no Parque Nacional de Uluru-Kata Djuta, na Austrália ${ }^{19}$. Essas concepções, em nível mundial, vem se tornando centrais para o debate sobre os SNS em AP nos diversos países em que essa relação é relevante.

O último Congresso Mundial de Conservação da Natureza foi realizado em Honolulu, no Havaí, em setembro de 2016. O tema do evento-O Planeta na Encruzilhada - faz um alerta para a gravidade da situação planetária, com o iminente risco de colapso dos ecossistemas, a ampliação dos efeitos das mudanças climáticas e as taxas cada vez mais elevadas de extinção da biodiversidade. A convocatória do evento conclama participantes de todo o mundo para a urgência na implementação de mecanismos que permitam transformar esse cenário. Afirma ainda que, entre o pessimismo desalentador - que alega ser tarde demais para se evitar uma catástrofe - e o otimismo cego - que nega a emergência da conjuntura atual -, há um caminho alternativo, que considera que a conservação da natureza e o progresso humano não são necessariamente excludentes ou incompatíveis. Não obstante, tal empreitada implica um grande desafio coletivo de mudança de paradigmas civilizatórios e de adoção de novas práticas que só obterão êxito com a construção de parcerias entre os mais diversos setores da sociedade ${ }^{20}$.

Nesse cenário, os SNS emergiram novamente como um tema-chave para o debate, inspirando e renovando a perspectiva de reconexão entre sociedade e natureza. A relação entre espiritualidade e conservação foi um dos assuntos de destaque nesse evento $^{21}$, no qual também foi aprovada a Resolução 033 - Reconhecimento dos Significados Culturais e Espirituais da Natureza em Áreas Protegidas. Essa diretiva não apenas reafirma as recomendações dos congressos anteriores sobre o tema, como reforça a importância de se construir capacidade institucional para promover o reconhecimento dos valores destacados anteriormente, a partir da formação dos atores que atuam diretamente na gestão das AP (IUCN, 2016, p. 83-84).

Além disso, também se destacou, nesse evento, a aprovação de uma das decisões possivelmente mais significativas na história da IUCN com relação à perspectiva de integração dos povos nativos nos

\footnotetext{
${ }^{18}$ Disponível em: <https://www.iucn.org/theme/protected-areas/about/promise-sydney>. Acesso em: fev. 2017.

${ }^{19}$ Onde, em 1985, em um ato simbólico que ficou conhecido como Handback, o governo nacional retornou os direitos à posse do território do parque ao povo aborígene.

${ }^{20}$ Disponível em: <iucnworldconservationcongress.org>. Acesso em: jul. 2016.

${ }^{21}$ Esse foi o tema de um dos cinco diálogos de alto nível (High Level Dialogues) realizados durante o evento, de uma jornada específica denominada Spirituality and Conservation Journey, e parte de outra mais ampla - a Nature and Culture Journey.
} 
debates sobre políticas públicas de conservação da natureza: a criação de uma categoria de filiação a essa rede voltada especificamente a contemplar esses grupos sociais, com o mesmo status das agências governamentais e organizações ambientalistas da sociedade civil (IUCN, 2016, p. 22).

\subsection{Desafios e potencialidades para a integração dos sitios naturais sagrados à gestão das áreas protegidas}

Diante dos elementos apresentados, vários autores consideram que, a despeito de não existir ainda uma legislação específica de âmbito mundial aplicável aos SNS, o conjunto de convenções, acordos, recomendações e resoluções internacionais direta ou indiretamente relacionados a essa temática representa uma sólida base legal orientadora para o reconhecimento e a proteção dessas áreas, ao redor do mundo. Entretanto, com algumas exceções, esse movimento parece ser ainda pouco conhecido e aplicado na maioria dos países, com parcos reflexos em políticas nacionais e ações governamentais.

Mas, esse contexto, conforme salienta Higgins-Zogib (2007), tanto pode ser vislumbrado como um problema ou como uma oportunidade para avançar na construção de apoio social para o movimento de proteção da natureza. Nessa última direção, as áreas protegidas têm sido constantemente reafirmadas como espaços estratégicos para a efetivação de iniciativas de salvaguarda dos SNS e para a integração dos valores culturais e espirituais aos processos de conservação da biodiversidade (Thorley \& Gunn, 2007; Wild \& McLeod, 2008; Pungetti et al., 2012).

Dessa forma, nos últimos anos, propostas para o reconhecimento dos SNS como parte dos sistemas oficiais de áreas protegidas passaram a ser defendidas por vários pesquisadores e organizações governamentais e não governamentais. E iniciativas com esse objetivo vêm sendo, progressivamente, implementadas em alguns países como a Índia, a China, a Rússia, a Austrália, os Estados Unidos, o México, a Guatemala e a Colômbia (Harmon \& Putney, 2003; Dudley et al., 2005; Thorley \& Gunn, 2007; Wild \& McLeod, 2008).

Essa estratégia de incorporar os SNS nas AP tem sido defendida prioritariamente como uma forma de assegurar a proteção dos sítios, especialmente quando esses vêm sofrendo crescentes ameaças externas. Mas também se reconhece que esse direcionamento pode trazer contribuições significativas para as áreas protegidas, ao potencializar o desenvolvimento de sinergias entre os processos de conservação da biodiversidade e os compromissos de participação e inclusão social das populações locais na sua gestão. Além disso, considerando a variedade de ambientes abrangidos pelos SNS e a sua ampla distribuição no planeta, alguns pesquisadores argumentam que o reconhecimento desses sítios como parte dos sistemas oficiais de AP poderia também contribuir para ampliar e aprimorar a representatividade dessa rede ao redor do mundo (Thorley \& Gunn, 2007).

Entretanto, integrar os SNS às políticas nacionais de proteção da natureza representa um desafio complexo - e as consequências dessa incorporação devem ser cuidadosamente avaliadas, bem como as suas possíveis desvantagens. Conforme discutem Dudley e colaboradores $(2010$, p. 20), "muitas perguntas permanecem sobre se, quando e como os SNS podem ser reconhecidos como áreas protegidas". Os esforços nessa direção só poderão avançar quando estratégias concretas para o diálogo entre administradores de AP e os grupos guardiões de SNS puderem ser asseguradas, agregando também outras parcerias nesse processo. 
Mas apenas o estabelecimento de canais de diálogo parece não ser suficiente para garantir o protagonismo dos guardiões dos SNS na tomada de decisão sobre medidas que afetem o uso dessas áreas. Como assinala Higgins-Zogib (2007), “a menos que os conservacionistas comecem a ver a natureza como as populações locais a entendem, as tentativas de trabalhar com esses grupos serão sempre imperfeitas". Nessa direção, é fundamental que se compreenda o importante papel que as AP desempenham na proteção de valores culturais e espirituais que, assim como a biodiversidade, também estão em risco. Da mesma maneira, é essencial que os elementos sagrados da natureza sejam tratados com cuidado e respeito, permitindo-se a integração de diferentes visões de mundo e de diversas formas de se relacionar com o ambiente ao cotidiano de gestão das áreas protegidas.

\section{Considerações finais}

Conforme discutido nesse artigo, a importância de se promover ações para o mapeamento e a salvaguarda de SNS vem sendo um tema de destaque em fóruns internacionais sobre políticas públicas, notadamente naqueles relacionados com estratégias de proteção da natureza. $\mathrm{Na}$ origem desse debate está o histórico de conflitos gerados na implantação de áreas protegidas sobre territórios de povos indígenas e outras populações tradicionais. Assim, no início da discussão sobre essa temática, a centralidade do debate foi pautada no reconhecimento desse passivo e na afirmação da importância dos SNS e dos valores culturais e espirituais a eles associados para a conservação da biodiversidade.

No decorrer das últimas décadas, entretanto, novas percepções sobre a necessidade de integração das dimensões biológica e cultural vêm se fortalecendo nas políticas públicas de proteção da natureza, refletindo o reconhecimento internacional dos direitos dos povos indígenas e da importância de saberes tradicionais para a conservação da biodiversidade. Os acordos firmados nos principais eventos mundiais com esse objetivo têm indicado a evolução do debate em curso, consolidando uma clara tendência para a incorporação dos SNS aos sistemas oficiais de áreas protegidas. Mas, para que se possa avançar nessa direção, é essencial que sejam respeitados os direitos dos guardiões dos sítios e assegurado o seu protagonismo na gestão desses territórios.

Diante disso, o êxito dessa proposta dependerá da capacidade de serem desenvolvidas estratégias inovadoras de gestão de áreas protegidas, capazes de integrar políticas públicas socioculturais e de proteção da natureza em iniciativas que busquem o fortalecimento de parcerias entre a gestão pública e os grupos sociais, contribuindo, assim, para a superação das tensões históricas mencionadas anteriormente. É primordial considerar, ainda, que esse é um processo em construção, que só poderá ser bem sucedido a partir do efetivo engajamento dos países onde a ocorrência de SNS é relevante, tanto para a aplicação das diretrizes internacionais na gestão dos sítios sagrados de seus territórios como para a formulação de políticas públicas nacionais com esse objetivo.

Há de se destacar, também, o papel fundamental da academia na reflexão e no debate crítico sobre essa temática, bem como para a investigação de casos concretos de SNS em áreas protegidas, o que demanda também a integração de distintos campos do conhecimento a uma perspectiva acadêmica interdisciplinar.

Assim, sem pretender esgotar o debate sobre o assunto, este artigo buscou despertar a atenção para o estudo e o reconhecimento dos SNS e formular um 
convite à reflexão acadêmica, nos planos teórico e aplicado, sobre uma temática que, apesar de muito antiga na história da humanidade, ainda representa uma novidade no campo das pesquisas científicas. Com essa mesma perspectiva, tencionou-se também contribuir para instigar a formulação de estratégias e instrumentos que possam ser adotados pelos diversos países para o reconhecimento dos valores

\section{Referências}

Barreto-Filho, H. T. Notas para uma história social das áreas de proteção integral no Brasil. In: Ricardo, F. (Org.). Terras indígenas e unidades de conservação da natureza: o desafio das sobreposições. São Paulo: Instituto Socioambiental, 2004. p. 53-63.

Beltrán, J. (Ed.). Indigenous and Traditional Peoples and Protected Areas: principles, guidelines and case studies. Gland, Switzerland: IUCN, 2000.

Bensusan, N. Diversidade e unidade: um dilema constante. Uma breve história da ideia de conservar a natureza em áreas protegidas e seus dilemas. In: Bensusan, N.; Prates, A. P. (Orgs.). A diversidade cabe na unidade? Áreas protegidas no Brasil. Brasília: IEB, 2014. p. 30-81.

Berkes, F. Sacred Ecology: traditional ecological knowledge and resource management. Philadelphia, USA: Taylor \& Francis, 1999.

Boff, L. Saber cuidar: ética do humano, compaixão pela Terra. Petrópolis: Vozes, 1999.

Borrini-Feyerabend, G.; Kothari, A.; Oviedo, G. Indigenous and local communities and protected areas: towards equity and enhanced Conservation. Gland, Switzerland: IUCN, 2004. (Best Practice Protected Areas Guidelines Series, 11).

Brosius, J. P. Indigenous Peoples and Protected Areas at the World Parks Congress. Conservation Biology, 18(3), 609-612, 2004.

Diegues, A. C. O mito moderno da natureza intocada. São Paulo: Hucitec, 2008. espirituais de suas áreas protegidas em políticas públicas nacionais, à luz das diretrizes e experiências mundiais. A complexidade que perpassa esse debate, além de delinear uma série de desafios a serem transpostos na implementação de políticas públicas, deve inspirar novos caminhos para a leitura da indissociabilidade entre sociedade e natureza e para o resgate da sacralidade dessa relação.

Dowie, M. Conservation refugees: the hundred-year conflict between global conservation and native peoples. Massachussetts: The MIT Press, 2011.

Dudley, N. (Ed.). Guidelines for Applying Protected Areas Management Categories. Gland, Switzerland: IUCN, 2008.

Dudley, N.; Higgins-Zogib, L.; Mansourian, S. Beyond Belief: linking faiths and Protected Areas to support biodiversity conservation. Cambridge: WWF, 2005.

Dudley, N.; Bhagwat, S.; Higgins-Zogib, L.; Lassen, B.; Verschuuren, B.; Wild, R. Conservation of biodiversity in sacred natural sites in Asia and Africa: a review of the scientific literature. In: Verschuuren, B.; Wild, R.; McNeely, J.; Oviedo, G. (Eds.). Sacred Natural Sites: conserving nature and culture. London: Earthscan, 2010. p. 19-32.

Dudley, N.; Groves, C.; Redford, K. H.; Solton, S. Where now for protected areas? Setting the stage for the 2014 World Parks Congress. Oryx, 48(4), 496-503, 2014.

Fernandes-Pinto, E.; Irving, M. A. Sítios Naturais Sagrados no Brasil: o gigante desconhecido. In: Hanazaki, N.; Herbst, D. F.; Ávila, J. V. C.; Heineberg, M. R.; Gomes, T. C. C. (Orgs.). Culturas e biodiversidade: o presente que temos e o futuro que queremos. Anais do VII Seminário Brasileiro sobre Áreas Protegidas e Inclusão, 2015. Florianópolis: Universidade Federal de Santa Catarina, 2015. p. 397-408.

Guattari, F. As três ecologias. Tradução Maria Cristina F. Bittencourt. Campinas, SP: Papirus, 1990.

Harmon, D.; Putney, A. D. (Eds.). The full values of parks: from economics to the intangible. Maryland: Rowman and Littlefield, 2003. 
Higgins-Zogib, L. Sacred sites and protected areas: an interplay of place-views. In: Haverkort, B; Rist, S. (Eds.). Endogenous development and bio-cultural diversity. Leusden: Compas Series, 2007. p. 287-298.

Irving, M. A. Sustentabilidade e o futuro que não queremos: polissemias, controvérsias e a construção de sociedades sustentáveis. Sinais Sociais, 9(26), 11-36, 2014.

International Union for Conservation of Nature and Natural Resources (IUCN). Benefits Beyond Boundaries. Proceedings of the Vth IUCN World Parks Congress. Gland, Switzerland: IUCN, 2005. Disponível em: $<$ https://portals. iucn.org/library/node/8662>. Acesso em: fev. 2017.

International Union for Conservation of Nature and Natural Resources (IUCN). Resolutions and Recommendations World Conservation Congress Barcelona, October 2008. Gland, Switzerland: IUCN, 2008. Disponível em: $<$ https:// portals.iucn.org/library/efiles/documents/WCC-4th-004. pdf $>$. Acesso em: jan. 2017.

International Union for Conservation of Nature and Natural Resources (IUCN). Resolutions and Recommendations World Conservation Congress, Jeju, Republic of Korea, September 2012. Gland, Switzerland: IUCN, 2012. Disponível em: $<$ https://cmsdata.iucn.org/downloads/2012_iucn_members_assembly_proceedings.pdf $>$. Acesso em: jan. 2017.

International Union for Conservation of Nature and Natural Resources (IUCN). IUCN Resolutions, Recommendations and other Decisions World Conservation Congress Honolulu, Hawai'i, United States of America, September 2016. Gland, Switzerland: IUCN, 2016. Disponível em: $<$ https:// portals.iucn.org/library/sites/library/files/documents/IUCN-WCC-6th-005.pdf>. Acesso em: fev. 2017.

Juffe-Bignoli, D.; Burgess, N. D.; Bingham, H.; Belle, E. M. S.; Lima, M. G.; Deguignet, M.; Bertzky, B.; Milam, A. N.; Martinez-Lopez, J.; Lewis, E.; Eassom, A.; Wicander, S.; Geldmann, J.; Soesbergen, A.; Arnell, A. P.; O'Connor, B.; Park, S.; Shi, Y. N.; Danks, F. S.; MacSharry, B.; Kingston, N. Protected Planet Report 2014. Cambridge, UK: UNEP-WCMC, 2014. Disponível em: <portals.iucn.org/library/ sites/files/documents/2014-043.pdf>. Acesso em: jul. 2016.

Larsen, P. B.; Wijesuriya, G. Interrelaciones entre naturaleza y cultura en el Patrimonio Mundial: últimas tendências. Revista Patrimônio Mundial, 75, abril 2015.
Lee, C.; Schaaf, T. The Importance of Sacred Natural Sites for Biodiversity Conservation. Proceedings of the International Workshop. Kunming e Xishuangbanna Biosphere Reserve, China, feb. 2003. Paris: UNESCO-MAB, 2003.

Leff, E. Saber ambiental. Petrópolis: Vozes, 2001.

Loureiro, C. F. B. Sustentabilidade e educação: um olhar da ecologia política. São Paulo: Cortez, 2012.

Maffi, L.; Woodley, E. Biocultural Diversity Conservation: A Global Sourcebook. Washington: Earthscan, 2010.

Mallarach, J. M. Recommendations from the "Promise of Sidney" with Significance to the Work of CSVPA. 2014. Disponível em:<csvpa.org/.../Promise-of-Sydney-Recommendations-with-relevan... >. Acesso em: jan. 2017.

Mallarach, J. M.; Papayannis, T. (Eds.). Protected Areas and Spirituality. Proceedings of the First Workshop of the Delos Initiative, Montserrat/Spain, 2006. Gland, Switzerland: IUCN, 2007.

Mallarach, J. M., Papayannis, T., Väisänen, R. (Eds.). The Diversity of Sacred Lands in Europe. Proceedings of the Third Workshop of the Delos Initiative, Inari/Aanaar, Finland 2010. Gland, Switzerland: IUCN, 2012.

Ministério do Meio Ambiente. A Convenção sobre Diversidade Biológica. Cópia do Decreto Legislativo n 2, de 5 de julho de 1992. Brasília: MMA, 2000. Disponível em: $<$ http:// www.mma.gov.br/estruturas/sbf_dpg/_arquivos/cdbport. pdf $>$. Acesso em: fev. 2017.

Morin, E.; Kern, A. B. Terra-pátria. 6. ed. Porto Alegre: Sulina, 2011.

Moscovici, S. Natureza: para pensar a ecologia. Rio de Janeiro: Mauad, 2007.

Nações Unidas. Declaração das Nações Unidas sobre Direitos dos Povos Indigenas. Rio de Janeiro, 2008. Disponível em: <http://www.un.org/esa/socdev/unpfii/documents/ DRIPS_pt.pdf $>$. Acesso em: fev. 2017.

Papayannis, T.; Mallarach, J. (Ed.).The Sacred Dimension of Protected Areas: Proceedings of The Second Workshop of the Delos Initiative, Ouranoupolis, Greece, 2007. Gland, Switzerland: IUCN, 2009.

Posey, D. (Ed.). Cultural and spiritual values of biodiversity. A comprehensive contribution to the UNEP Global Biodiversity Assessment. London, 1999. 
Pungetti, G.; Oviedo, G.; Hooke, D. Sacred Species and Sites: advances in biocultural conservation. Cambridge: Cambridge University Press, 2012.

Schaaf, T.; Lee, C. (Ed.).Conserving Cultural and Biological Diversity: The Role of Sacred Natural Sites and Cultural Landscapes. Proceedings of UNESCO-IUCN International Conference, Tokyo, 2006.

Secretariat of the Convention on Biological Diversity. Akwé: Kon Voluntary Guidelines for the Conduct of Cultural, Environmental and Social Impact Assessment regarding Developments Proposed to Take Place on, or which are Likely to Impact on, Sacred Sites and on Lands and Waters Traditionally Occupied or Used by Indigenous and Local Communities. Montreal: CDB, 2004. (CBD Guidelines Series).

Stevens, S. Conservation through Cultural Survival: Indigenous People and Protected Areas. Washington DC: Island Press, 1998.

Thorley, A.; Gunn, C. M. Sacred Sites: an overview. London: The Gaia Foundation, 2007.

United Nations Educational, Scientific and Cultural Organization (UNESCO). Natural Sacred Sites: cultural diversity and biological diversity. Abstracts International Symposium. Paris: UNESCO, 1998.

UNESCO - United Nations Educational, Scientific and Cultural Organization (UNESCO). Declaração Universal sobre a Diversidade Cultural. Paris: UNESCO, 2001. Disponível em: $<$ http://unesdoc.unesco.org/images/0012/001271/127160por.pdf>. Acesso em: jul. 2014.
United Nations Educational, Scientific and Cultural Organization (UNESCO). Convenção para Salvaguarda do Patrimônio Cultural Imaterial. Paris: UNESCO, 2003. Disponível em: <http://www.unesco.org/culture/ich/doc/ src/00009-PT-Portugal-PDF.pdf $>$. Acesso em: jul. 2014.

United Nations Educational, Scientific and Cultural Organization (UNESCO). Convenção sobre a Proteção e Promoção da Diversidade das Expressões Culturais. Paris: UNESCO, 2005. Disponível em: $<\mathrm{http}: / /$ unesdoc. unesco.org/images/0015/001502/150224por.pdf $>$. Acesso em: jul. 2014.

Verschuuren, B. Believing is seeing: integrating cultural and spiritual values in conservation management. Gland, Switzerland: IUCN, 2007.

Verschuuren, B.; Wild, R. Safeguarding sacred natural sites: sustaining nature and culture. Langscape, 2(2), 12-19, 2012.

Verschuuren, B.; Mallarach, J. M.; Oviedo, G. Sacred Sites and Protected Areas. IUCN World Commission on Protected Areas Task Force on Protected Area Categories. Andalusia, Spain, maio 2007.p.7-11.

Verschuuren, B.; Wild, R.; McNeely, J.; Oviedo, G. (Eds.). Sacred Natural Sites: conserving nature and culture. London: Earthscan, 2010.

West, P. C.; Brechin, S. R. Resident peoples and National Parks: social dilemmas and strategies in international conservation. Tucson, USA: University of Arizona Press, 1991.

Wild, R.; McLeod, C. Sacred Natural Sites: Guidelines for Protected Areas Managers. Gland, Switzerland: IUCN, 2008. 